\title{
Immediate Tooth Replacement: Strategies for Success
}

\section{Randall Warkentin}

Part Time Instructor, General Practice Clinic, University of Manitoba, Winnipeg Manitoba, Private Practice, Morden, Manitoba Canada

Correspondece: Randall Warkentin, Part Time Instructor, General Practice Clinic, University of Manitoba, Winnipeg Manitoba Boundary Trails Dental Center, 401 North Railway Street, Morden, Manitoba, Canada, R6M 1S8, Phone: 2048226259 e-mail: ykwmac@gmail.com

\begin{abstract}
The replacement of a single anterior tooth is a common procedure performed in contemporary implant dentistry. Placing an implant immediately following tooth extraction affords several advantages to the patient compared with a staged approach. This article illustrates a case of an extraction and immediate implant placement, emphasizing some of the key principles involved in the procedure.
\end{abstract}

Keywords: Immediate tooth replacement, implants.

\section{INTRODUCTION}

The replacement of a single anterior tooth can be a rewarding and valued service that we can provide for our patients. It is also one of the most challenging procedures, we perform due to the esthetic requirements of the maxillary anterior region. ${ }^{1,2}$ In addition to the usual considerations of shade and contours that every anterior restoration has, implants must be placed in the ideal position to achieve a proper emergence profile. ${ }^{1-3}$ The edentulous site is often compromised by the loss of soft and hard tissues that accompany tooth loss. ${ }^{4-7}$ Achieving ideal soft tissue contours and interdental papillae frequently requires augmentation of the hard and soft tissues. ${ }^{2,7,8}$ It is often easier to preserve these tissues by placing an implant immediately following tooth extraction than to restore them after they have been lost. ${ }^{3,9,10}$

Implant placement immediately following tooth extraction affords several advantages. The papillae and bony architecture are preserved, improving the esthetic outcome and reducing the need for augmentation of these tissues. ${ }^{9-12}$ There are fewer appointments required, lesser discomfort, and greater convenience for the patient.

However, the procedure may have some risks. Micromovement of the implant during the healing period may prevent it from integrating. ${ }^{4,13}$ Overloading of the implant is more likely to occur, if a provisional restoration is placed at the time of surgery than if a healing abutment is placed. Overload is least likely when a cover screw is used. ${ }^{14}$
There are several key principles involved in placing an implant immediately following tooth extraction.

\section{Atraumatic Extraction}

The facial bony plate is usually very thin and easily fractured during the extraction procedure. Periotomes or luxators are used to gently remove the tooth. Pressure is applied apically at the mesial and distal aspects of the tooth, taking care not to force it labially. ${ }^{15}$

\section{Evaluate the Socket}

A curette, is used to gently explore the labial aspect of the socket for fenestrations or fractures. If the labial wall is intact and there is no sign of infection, immediate implant placement will have a higher likelihood of success. ${ }^{3,15}$ If the labial plate is not intact or there is chronic infection present, a ridge preservation procedure should be done and implant placement delayed. ${ }^{2,3}$

\section{Place the Implant along the Palatal Wall}

The thicker palatal walls resist osteotomy drills, which may inadvertently be directed labially, thus compromising the thin labial bone. To prevent this from happening, and to take advantage of the thicker palatal bone, a new apex and pathway for the osteotomy drills is created using a round bur or a Lindemann bur. Lateral pressure is placed against the palatal wall during the osteotomy preparation. A bone tap may be used in dense bone to prevent labial displacement of the implant during insertion. ${ }^{4}$ 


\section{Use a Handpiece to Place the Implant}

Using a handpiece rather than a ratchet helps prevent the implant from wobbling and damaging the labial bone. A ratchet or torque wrench can be used to manually drive it into its final position..$^{1-3}$

\section{Evaluate the Stability of the Implant}

A minimum of $35 \mathrm{Ncm}$ of torque is needed to provide sufficient stability to safely place a provisional restoration. ${ }^{15,16}$ Based on the amount of stability the implant exhibits, a decision can be made to place either a provisional restoration, a transmucosal healing abutment or a low profile cover screw for a 2 stage procedure. ${ }^{14}$ If a restoration is placed, it is kept out of occlusion and the patient is instructed to avoid function on that tooth. ${ }^{15}$

This article illustrates a typical case involving the principles and procedures described-

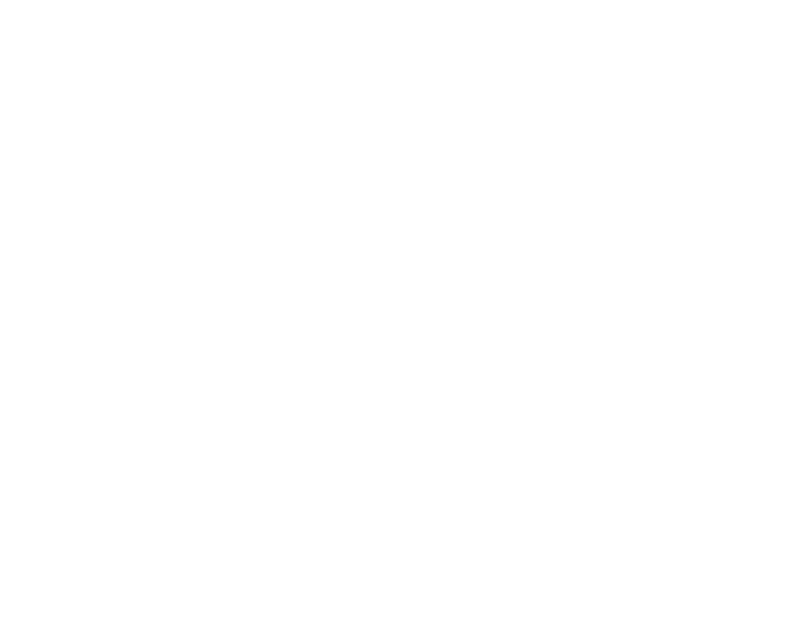

Fig. 1: A 57-year-old female patient presented with her lateral incisor fractured off below the gum line. Notice the wear facets on the lower teeth. The use of a night guard will be mandatory following treatment

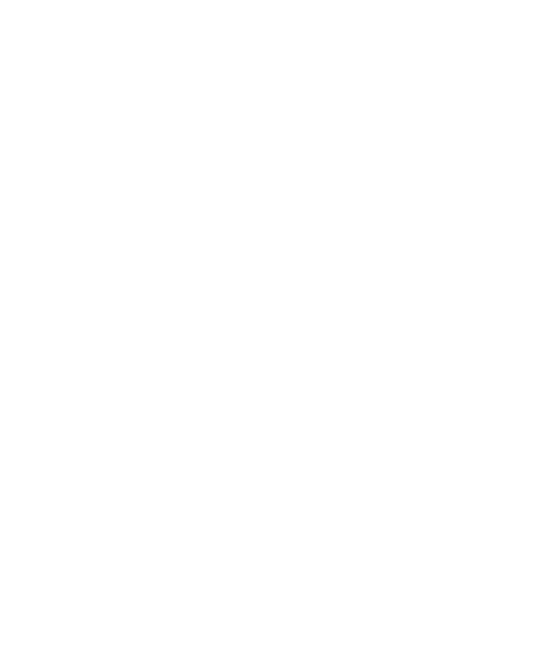

Fig. 2: Pretreatment radiograph. The tooth had previously been endodontically treated and restored with a fiber post and porcelain jacket crown. The postfractured along with the tooth

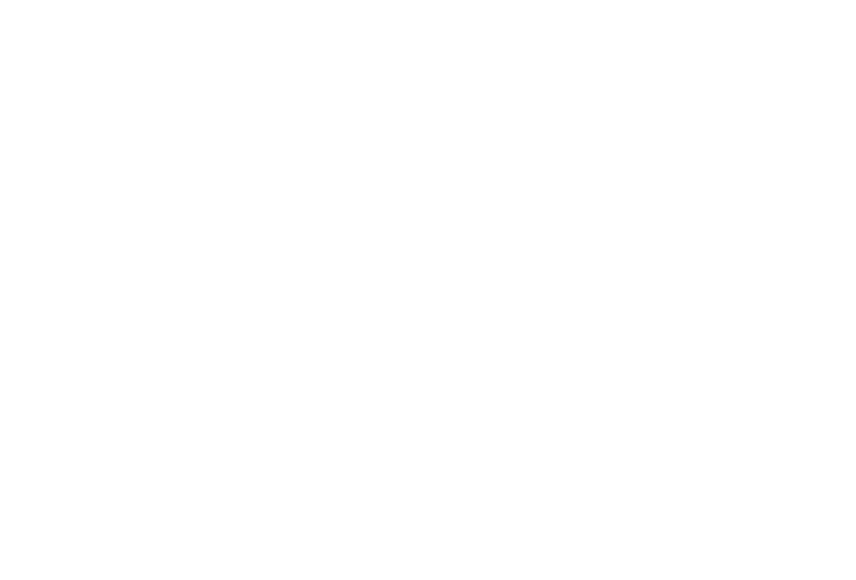

Fig. 3: The root was extracted atraumatically with periotomes. The forceps were simply used to retrieve the tooth after it had been thoroughly luxated

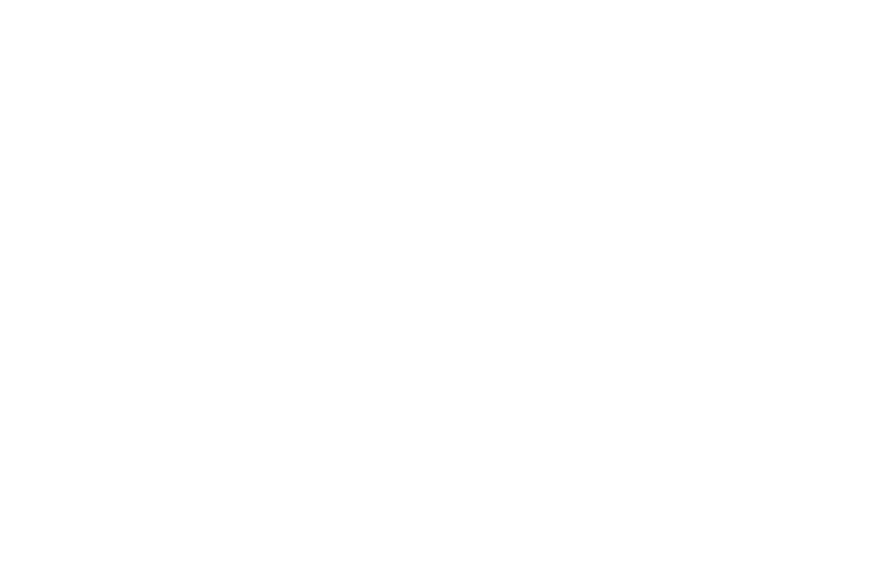

Fig. 4: A curette is used to debride the socket. The facial plate was found to be intact and a decision was made to proceed with the implant placement

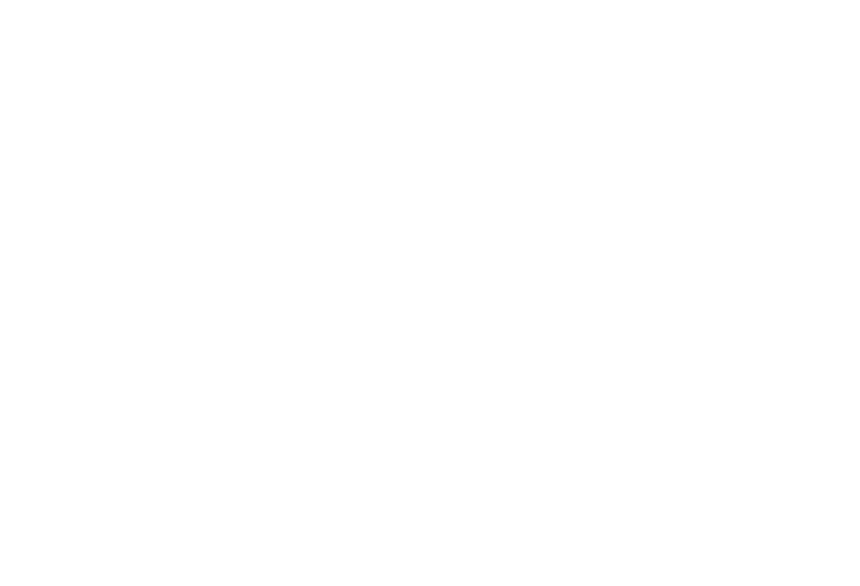

Fig. 5: A Lindemann bur is used to establish a new apex in the socket and a pathway for the osteotomy drills along the palatal aspect. Care must be taken to avoid damaging the fragile facial bony plate of the socket. The drill is centered mesiodistally and exits in line with the incisal edge 


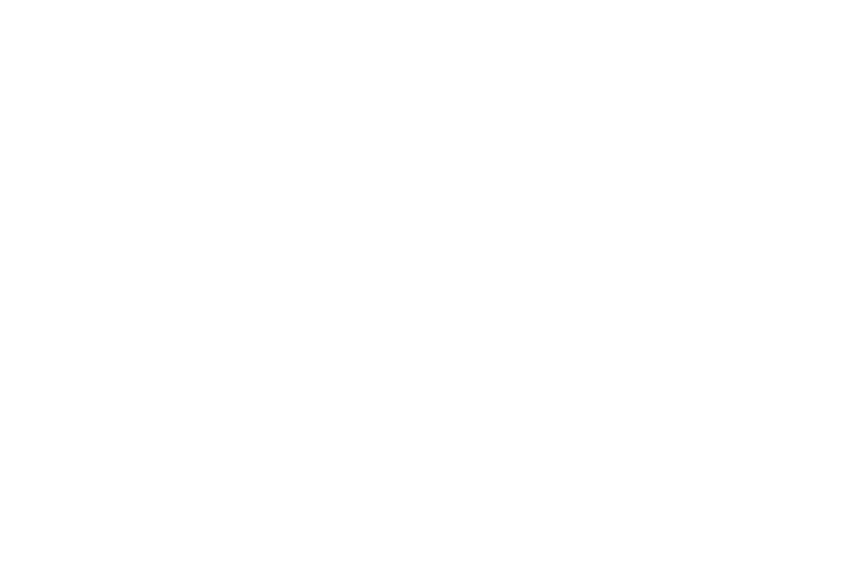

Fig. 6: The initial $2 \mathrm{~mm}$ pilot drill in the proposed position. A drill extender extends the operating length of the drill and provides access between the adjacent teeth

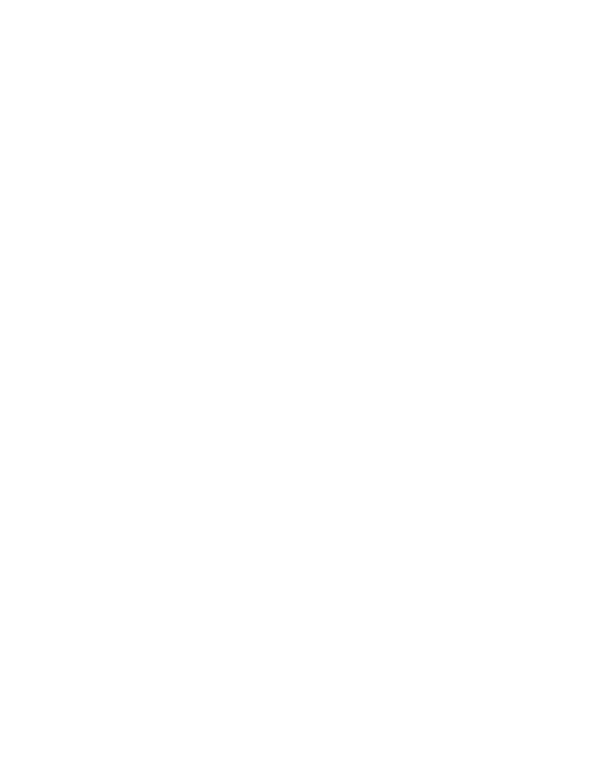

Fig. 7: A radiograph taken at this stage allows the evaluation of the pilot drill position and depth. Minor adjustments can easily be made

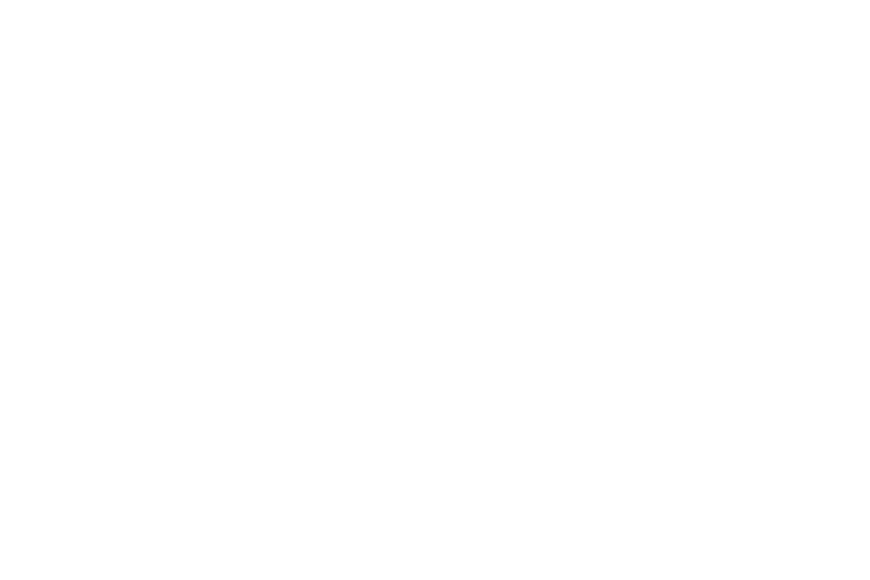

Fig. 8: As the osteotomy proceeds, lateral pressure is placed against the palatal wall of the socket to prevent compromising the thin facial wall

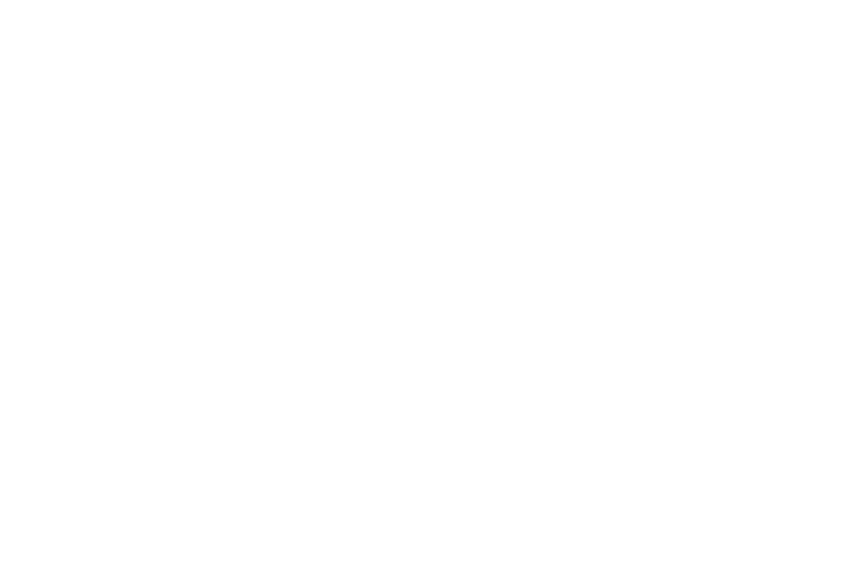

Fig. 9: A $4.6 \times 15$ mm Biohorizons Tapered Internal implant is placed using a high torque handpiece at $30 \mathrm{rpm}$. The handpiece is used instead of a ratchet to prevent the implant from wobbling and damaging the labial wall. A finger palpates the facial bone to make sure it does not fracture during the placement of the implant. Lateral pressure is used against the palatal aspect of the socket

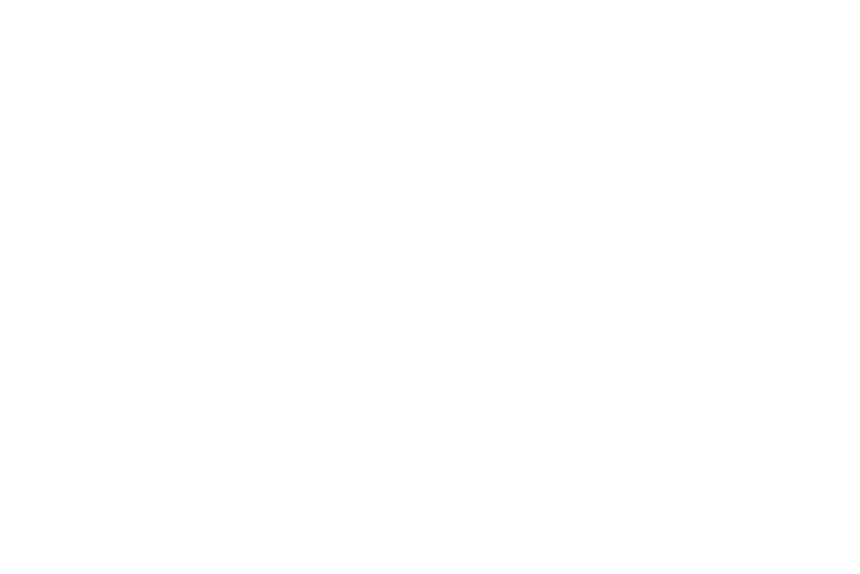

Fig. 10: A ratchet is used to drive the implant into its final position. The ideal platform level is $3 \mathrm{~mm}$ below the gingival margin with the center of the implant located directly under the incisal edge of the crown

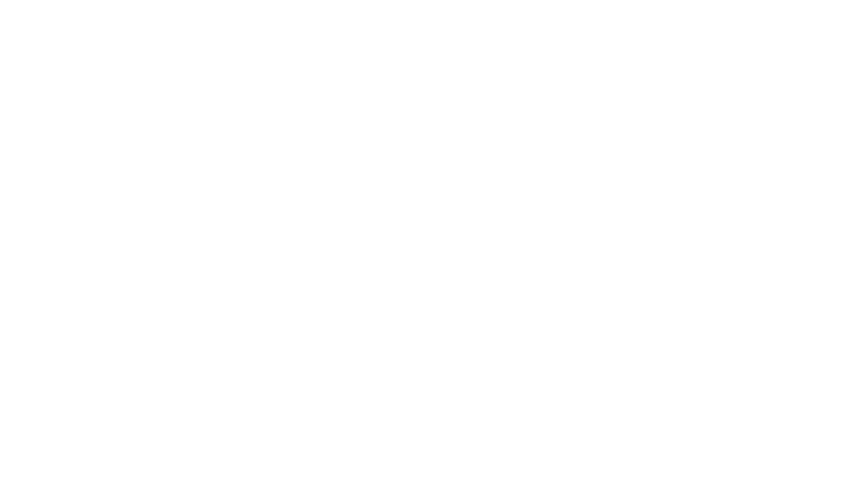

Fig. 11: The implant is seated completely 


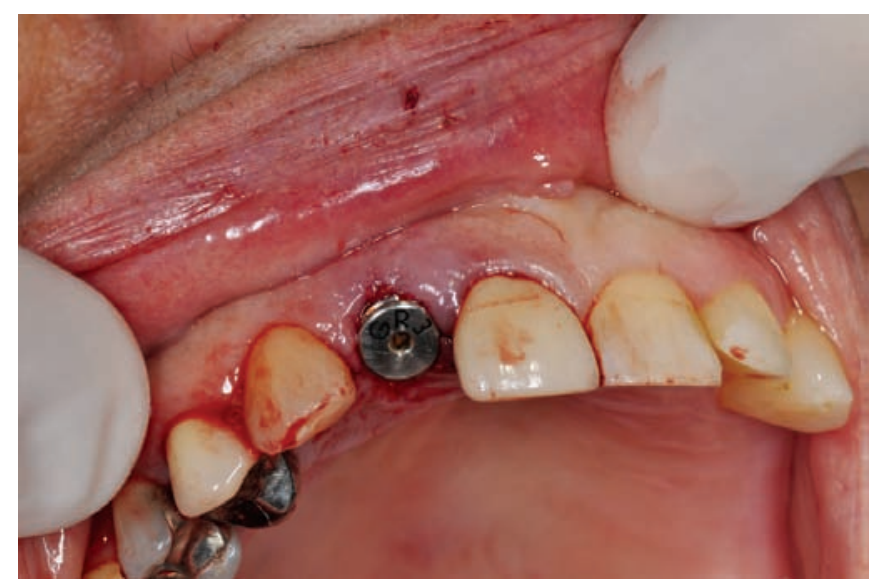

Fig. 12: A healing abutment was placed allowing us to avoid a 2nd stage surgical procedure

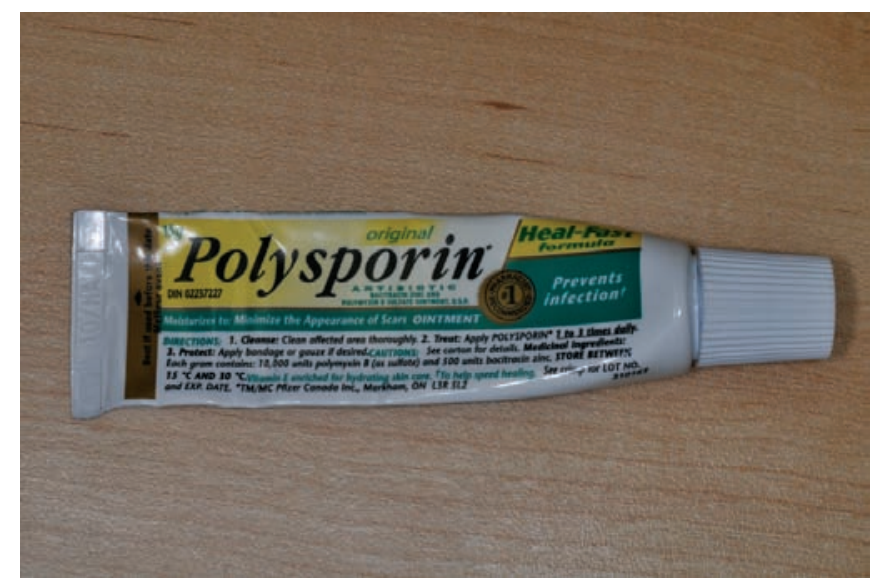

Fig. 13: An antibiotic ointment is used under the healing abutment to fill the microgap

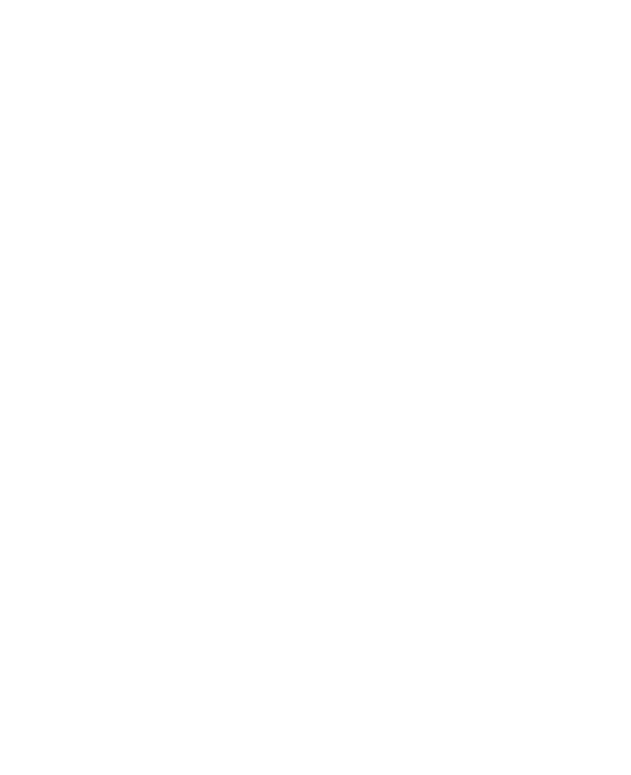

Fig. 14: Postoperative radiograph

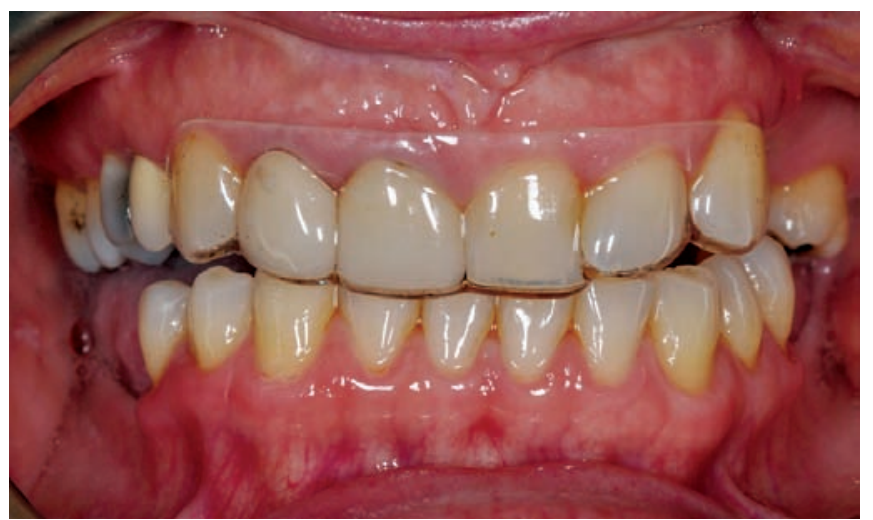

Fig. 15: The patient's actual crown is used as the temporary removable restoration. It is embedded in a clear vacuum formed appliance and relieved around the healing abutment

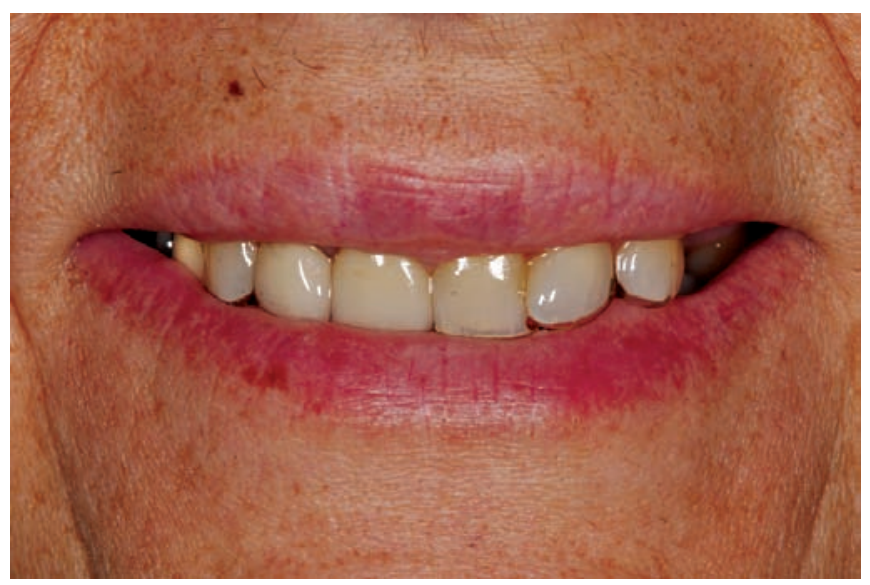

Fig. 16: The patient's smile looks exactly the same as it did before her crown fractured

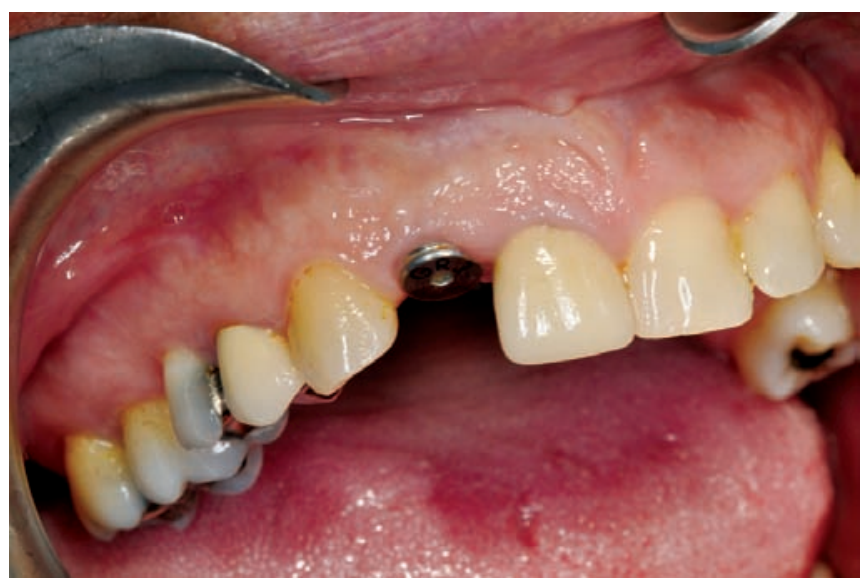

Fig. 17: After 4 months the prosthetic phase can begin. The tissues are healthy and the preoperative soft tissue contours have been preserved 


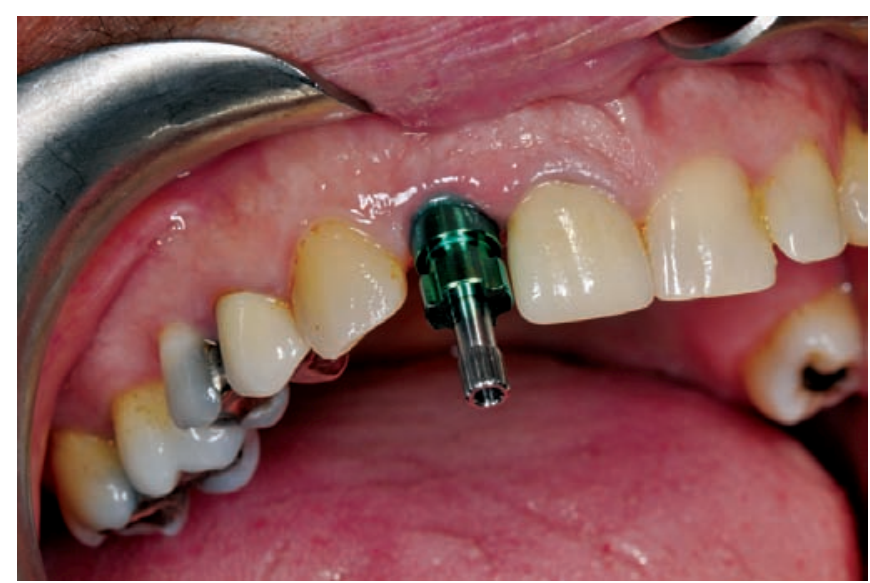

Fig. 18: A direct transfer coping is screwed onto the implant body

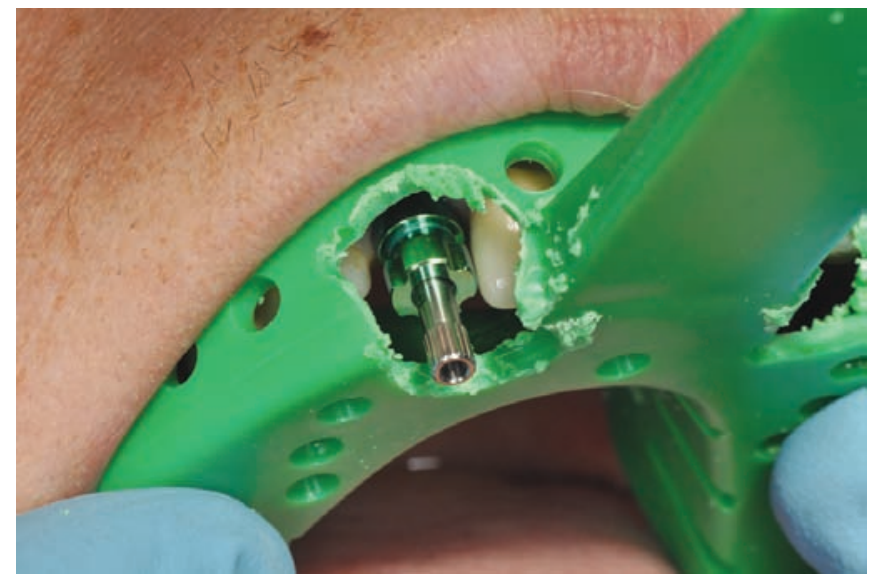

Fig. 19: A standard impression tray is quickly transformed into a modified open tray with a high-speed bur

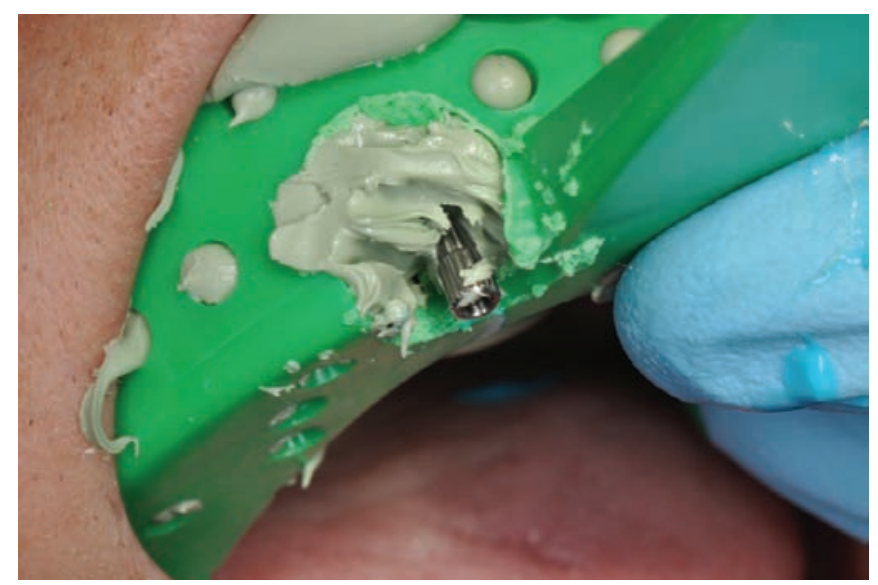

Fig. 20: A full arch impression is taken with the open tray technique. Mounted casts are sent to the lab with a prescription for a custom abutment and the final all ceramic crown
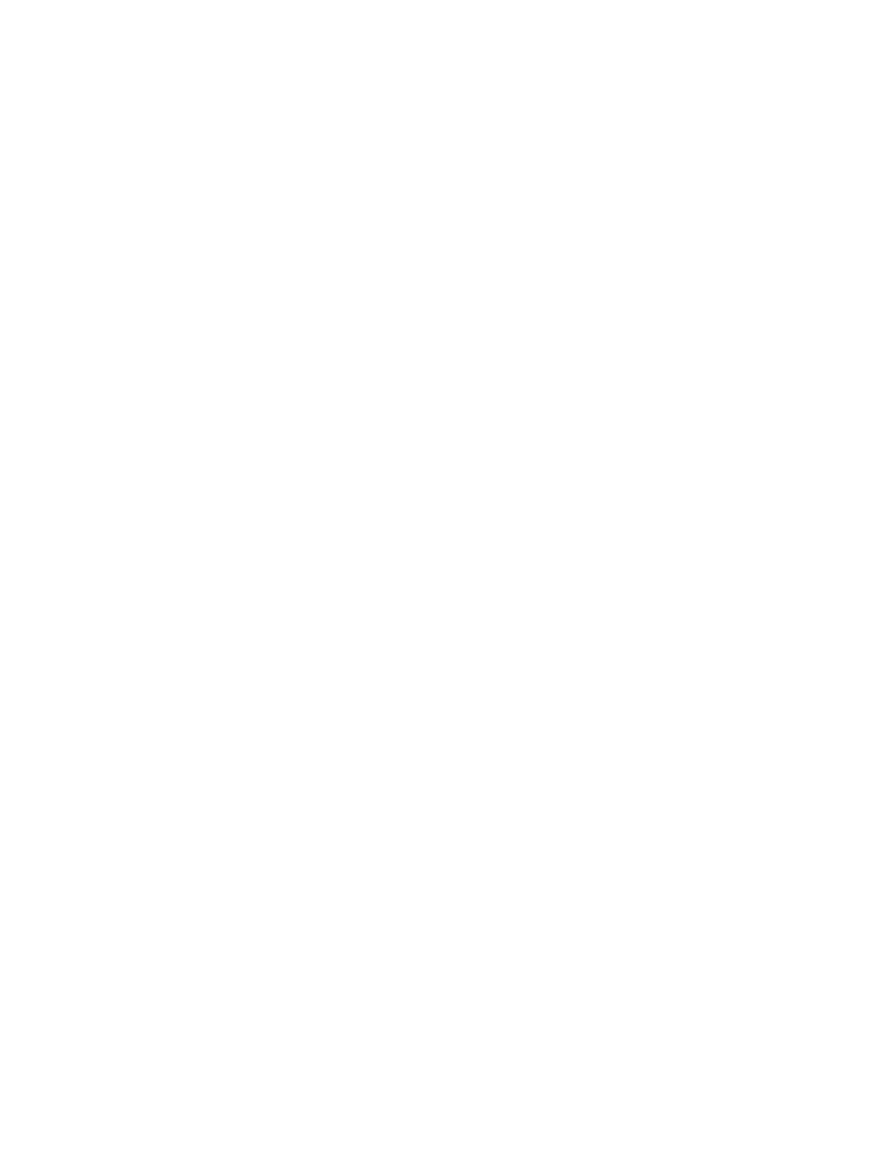

Figs 21A and B: The abutment screw threads are coated with a dental thread locker

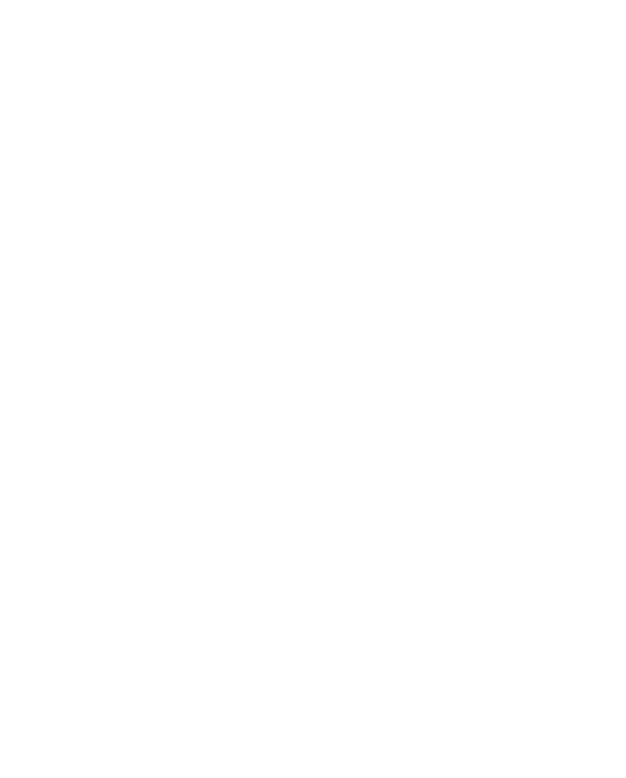

Fig. 22: Postoperative radiograph 


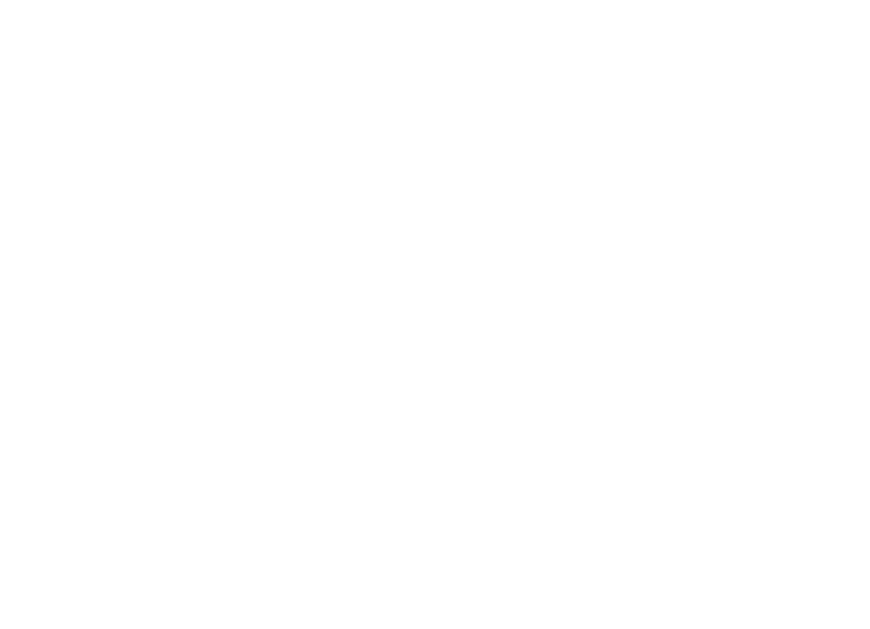

Fig. 23: Final result

\section{REFERENCES}

1. Bashutski JD, Wang HL. Common implant esthetic complications. Implant Dent Dec 2007;16(4):340-48.

2. Buser D, Martin W, Belser UC. Optimizing esthetics for implant restorations in the anterior maxilla: Anatomic and surgical considerations. Int J Oral Maxillofac Implants 2004;19:43-61.

3. Funato A, Salama MA, Ishikawa T, Garber DA, Salama H. Timing, positioning, and sequential staging in esthetic implant therapy: A four-dimensional perspective. Int J Periodontics Restorative Dental Aug 2007;27(4):313-23.

4. Misch CE. Contemporary Implant Dentisry, Mosby 1999.

5. Van der Weijden F, Dell'Acqua F, Slot DE. Alveolar bone dimensional changes of post-extraction sockets in humans: A systematic review. J Clin Periodontol. Dec 2009;36(12): 1048-58.

6. Schropp Lars, Wenzel Ann, Kostopoulos Lambros, Karring Thorkild. Bone healing and soft tissue contour changes following single-tooth extraction: A clinical and radiographic 12-month prospective study. The International journal of periodontics and restorative dentistry 2003;23(4):313-23.

7. Nevins M, Camelo M, De Paoli S, Friedland B, Schenk RK, Parma-Benfenati S, Simion M, Tinti C, Wagenberg B. A study of the fate of the buccal wall of extraction sockets of teeth with prominent roots. Int J Periodontics Restorative Dental Feb 2006;26(1):19-29.

8. Zetu L, Wang H-L, Management of Inter-dental/lnter-implant Papilla. J CIin Periodontol 2005;32:831-39.

9. Block MS, Mercante DE, Lirette D, Mohamed W, Ryser M, Castellon P. Prospective evaluation of immediate and delayed provisional single tooth restorations. J Oral Maxillofac Surg Nov 2009;67(11 Suppl):89-107.

10. Arlin ML. Immediate placement of osseointegrated dental implants into extraction sockets: Advantages and case reports. Oral Health Jul 1992;82(7):19-20.

11. Canullo L, Rasperini G. Preservation of peri-implant soft and hard tissues using platform switching of implants placed in immediate extraction sockets: A proof-of-concept study with 12- to 36-month follow-up. Int J Oral Maxillofac Implants NovDec 2007;22(6):995-1000.

12. Mijiritsky E, Mardinger O, Mazor Z, Chaushu G. Immediate provisionalization of single-tooth implants in fresh-extraction sites at the maxillary esthetic zone: Up to 6 years of follow-up. Implant Dent Aug 2009;18(4):326-33.

13. Brunski JB et al. The influence of functional use of endosseous implants on the tissue-implant interface: Histological aspects, J Dent Res 1979; 58:1953.

14. Chaushu G, Chaushu S, Tzohar A, Dayan D. Immediate loading of single-tooth implants: Immediate versus non-immediate implantation. A clinical report. Int J Oral Maxillofac Implants. Mar-Apr 2001;16(2):267-72.

15. Garber DA, Salama MA, Salama H. Immediate total tooth replacement. Compend Contin Educ Dent. Mar 2001;22(3): 210-6, 218.

16. Ottoni JM, Oliveira ZF, Mansini R, Cabral AM. Correlation between placement torque and survival of single-tooth implants. Int J Oral Maxillofac Implants. Sep-Oct 2005;20(5):769-76. 